Pledgets failed in $23 \%$ of those with initial insertion under anaesthesia compared with $38 \%$ in those without anaesthesia. The length of time the child had had the ingrown toenail did not influence success. Appearance was excellent in those attending follow up clinics.

\section{Discussion}

This condition receives no attention in most paediatric surgical textbooks. It is mentioned in a book by Filston $^{3}$ and another edited by Jones and Woodward. ${ }^{4}$ Pledget management is recommended in the latter, but no references are cited and no results reported. Gutter treatment for ingrown toenail in adults achieved success in 20 patients out of 36 studied after a one year follow up and the treatment was proposed for use in general practice. ${ }^{2}$ Other forms of treatment studied include phenol, ${ }^{5}$ cryosurgery, ${ }^{6}$ and radical surgery in adult populations with success varying between $56 \%$ and $95 \%$.

In children, ingrown toenail occurs most commonly in the older child (10 to 13 years old), and seems different to the congenital variety. We believe severe cutting or tearing with angling of the edges to be common precipitating factors. Most of our patients had this type of nail at presentation. Friction, trauma, and tight fitting shoes are other possible aetiological factors, yet only 14 of the children we reviewed had bilateral ingrown toenail and the lateral side was most frequently affected.

Children over 7 year old, and parents of those children who were younger, were easily taught to insert pledgets and how to take care of their nails correctly. Once this had been learned patients could institute treatment for the contralateral nail if or when it became symptomatic (found in two patients).

Failure was reduced ( $38 \%$ to $23 \%$ ) if the initial insertion was performed under anaesthesia; this was probably due to the thorough cleansing and deep insertion that was possible. The nail edge soon became raised and clear of the soft tissues and subsequent insertions were easy. The appearance was excellent, there was no loss of nail width or soft tissue, and no visible difference between the treated and the contralateral nail.

We propose this form of treatment as an acceptable conservative approach to the management of ingrown toenail in children.

\footnotetext{
References

${ }^{1}$ Anonymous. Ingrowing toe nails [Editorial]. Lancet 1984;ii:268.

2 Wallace WA, Milne DD, Andrew T. Gutter treatment for ingrowing toe nails. $\mathrm{Br}$ Med $J$ 1979;ii:168-71.

${ }^{3}$ Filston HC. Surgical problems in children, recognition and referral. St Louis: CV Mosby Co. 1982.

4 Staff of Royal Children's Hospital, Melbourne. In: Jones PG, Woodward AA, eds. Clinical paediatric surgery: diagnosis and management. 3rd ed. Melbourne: Blackwell, 1987:141.

${ }^{5}$ Morkane AJ, Robertson RW, Iglis GS. Segmental phenolization of ingrowing toe nails: a randomized controlled study. $\mathrm{Br} J$ Surg 1984;71:526-7.

${ }^{6}$ Silverman SH. Cryosurgery for ingrowing toenail. Journal of the Royal College of Surgeons of Edinburgh 1984;29:289-91.
}

Correspondence to Miss B Connolly, Children's Research Centre, Our Lady's Hospital for Sick Children, Crumlin, Dublin 12.

Received 3 August 1987

\title{
Acrodermatitis chronica atrophicans
}

\section{NADAL, R GUNDELFINGER, U FLUELER, AND E BOLTSHAUSER}

Department of Pediatrics, University of Zurich, Switzerland

SUMMARY Two cases of acrodermatitis chronica atrophicans associated with Borrelia burgdorferi infection are reported; to our knowledge these are the first cases reported in children.

Lyme disease is a complex multisystem disorder which usually begins with erythema chronicum migrans, a creeping annular erythematous skin lesion. Weeks to months later some patients develop meningitis, cranial or peripheral neuropathies, myocarditis, or arthritis. The illness is caused by the tick borne spirochete Borrelia burgdorferi. ${ }^{1}$ Because acrodermatitis chronica atrophicans is also associated with $B$ burgdorferi infection, it is now considered to be a late manifestation of Lyme disease. ${ }^{2}$ Acrodermatitis chronica atrophicans is usually seen in adults aged 30 to 60 years; we now report two cases in children.

\section{Case reports}

CASE 1

A 10 year old boy was referred because of darkened 
skin over the right lower leg that had been present for a few weeks. No accompanying symptoms such as fever or pain were reported but the boy remembered a tick bite a year before. On examination the skin over the knee, lower leg, and dorsum of the foot was livid with some oedematous and hyperaemic areas. Over the ankle the skin was dry and dystrophic. The erythrocyte sedimentation rate was $22 \mathrm{~mm}$ in the first hour, and the white cell count and differential were normal. The $B$ burgdorferi titre in the serum was $1 / 4096$ (normal below 1/64) ${ }^{3}$ Histological examination of a skin biopsy specimen showed a thin epidermis with a strongly pigmented stratum basale and perivascular patchy infiltration by lymphocytes, plasma cells, and histiocytes. Culture of the skin for $B$ burgdorferi was negative. ${ }^{2}$ Treatment was started with benzylpenicillin 12 million units $/ \mathrm{m}^{2} /$ day intravenously for four weeks, and within a week the hyperpigmentation decreased and the oedema and hyperaemia disappeared. Six months later the skin was almost normal. The $B$ burgdorferi titre remained high at $1 / 4096$.

CASE 2

A 12 year old boy was referred because of violet

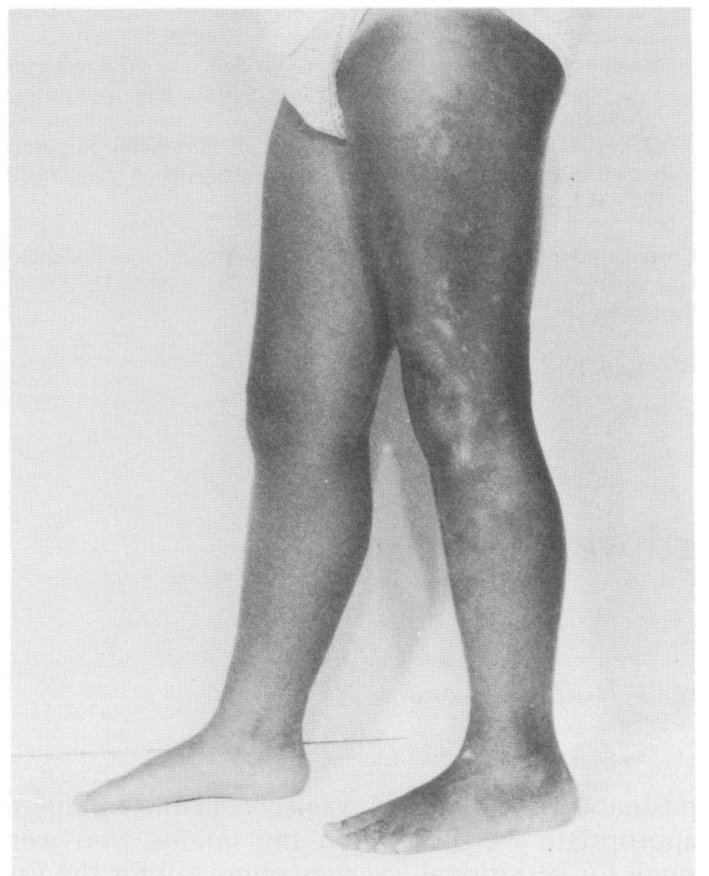

Fig 1 Case 2 before treatment: note hyperpigmentation of left leg with vitiligo like patches.

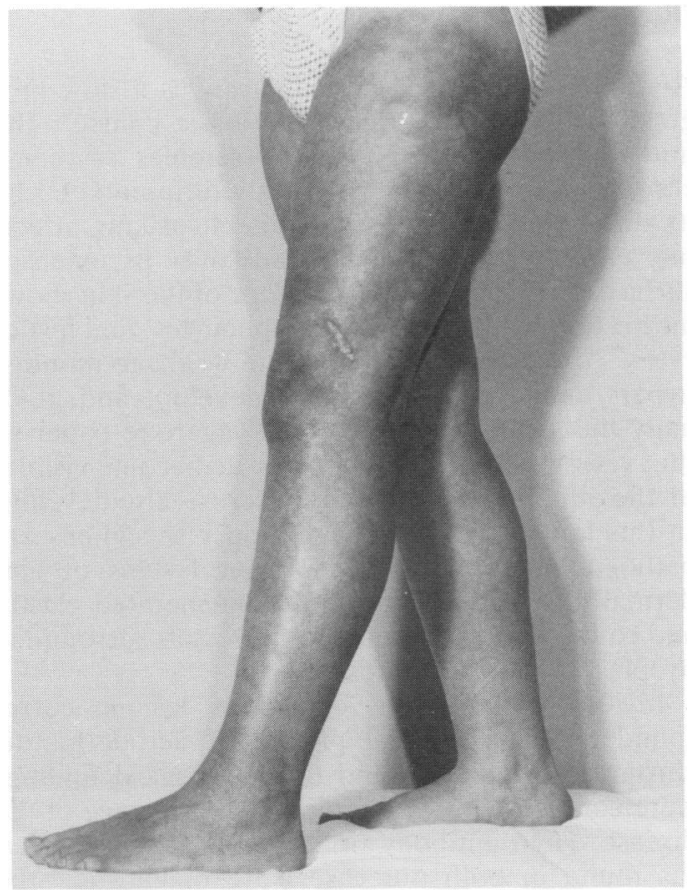

Fig 2 Case 2 six morutus ufter treatment with

benzylpenicillin; linear streak above knee is a biopsy scar.

discolouration of the skin of his left leg. A year earlier the patient had noticed induration of the subcutaneous tissue over the left quadriceps muscle. Later the skin over this area darkened and the lesion spread to the lower leg. There was no pain, functional impairment, or fever, and no history of a tick bite. In addition to this hyperpigmentation and induration of the skin and subcutaneous tissue, a few vitiligo like patches were noted, some of which were atrophic (fig 1). Some areas felt warm. The circumferences of the left upper and lower leg were $2 \mathrm{~cm}$ less than the right. The erythrocyte sedimentation rate was $20 \mathrm{~mm}$ in the first hour; white cell count and differential were normal. The $B$ burgdorferi titre in the serum was $1 / 4096$. Histological examination of the affected skin showed pronounced oedema of the corium, and perivascular patchy round cell infiltrates consisting mainly of lymphocytes. Cultures of the skin for $B$ burgdorferi were negative. Treatment was started with benzylpenicillin 12 million units $/ \mathrm{m}^{2} /$ day for four weeks, and within a week the dark skin areas lightened and the induration decreased. After six months the skin had reverted to normal (fig 2) but the differences in leg circumferences still persisted. The $B$ burgdorferi titre in serum remained high at 1/2048. 


\section{Discussion}

Acrodermatitis chronica atrophicans is a slow progressive disease that runs a biphasic course ${ }^{4}$ : the initial or inflammatory stage resembles erythema chronicum migrans, but is clearly differentiated by its diffuse or localised erythema. It usually affects one extremity and later spreads over its extensor surface. In this phase the histology of the skin shows infiltration by plasma cells, lymphocytes, and histiocytes. After periods varying from weeks to months, hyper- and hypopigmentation develop, and gradually the skin becomes frail like cigarette paper so that vessels and subcutaneous tissue become visible; on the other hand fibrosis and sclerosis also develop. In this late or atrophic stage biopsy specimens are pathognomonic showing the typical signs of epidermal atrophy, damaged and degenerated elastin and collagen, and dilated dermal vessels surrounded by plasma cell infiltrates.

In our patients the cutaneous lesions corresponded to the clinical picture of acrodermatitis chronica atrophicans, and the histological findings were compatible with the inflammatory stage of the disease. High antibody titres against $B$ burgdorferi (as found in both our cases) are diagnostic, ${ }^{3}$ the negative skin biopsy culture is not surprising, because isolation of the organism is notoriously difficult. $^{2}$

A history of tick bite (absent in case 2) is not mandatory in diagnosing diseases caused by $B$ burgdorferi because the bite is often overlooked or forgotten, and tabanids and mosquitoes may also harbour the pathogen..$^{5}$ Our patients had no other signs or symptoms of Lyme disease.

Benzylpenicillin has been reported to be effective in the inflammatory stage of acrodermatitis, but recommended treatment regimens differ. ${ }^{4}$ Because high doses of penicillin given parenterally have been successful in the later stages of Lyme disease, ${ }^{6}$ we prescribed intravenous benzylpenicillin 12 million units $/ \mathrm{m}^{2} /$ day for four weeks. Clinically this treatment was successful, although the skin changes had not completely disappeared at the time of writing. Raised antibody titres may persist for six to 12 months after treatment. ${ }^{3}$ As in late syphilis, it may be that the time taken to achieve seronegativity after acrodermatitis depends on the duration of the untreated infection.

Our observations show that acrodermatitis chronica atrophicans associated with $B$ burgdorferi may occur in childhood. Paediatricians should therefore be aware of this disorder because early diagnosis and treatment are important.

\section{References}

1 Steere AC, Malawista SE. Lyme disease. In: Mandell GL, Douglas RG, Bennet JE, eds. Principles and practice of infectious diseases. New York: John Wiley \& Sons, 1985: 1343-9.

2 Asbrink E, Hovmark A, Hederstedt B. The spirochetal etiology of acrodermatitis chronica atrophicans Herxheimer. Acta Derm Venereol (Stockh) 1984;64:506-12.

${ }^{3}$ Asbrink E, Hovmark A, Hederstedt B. Serologic studies of erythema chronicum migrans Afzelius and acrodermatitis chronica atrophicans with indirect immunofluorescence and enzyme-linked immunosorbent assays. Acta Derm Venereol (Stockh) 1985;65:509-14.

4 Burgdorf WHC, Worret W-I, Schultka O. Acrodermatitis chronica atrophicans. Int J Dermatol 1979;18:595-601.

${ }^{5}$ Magnarelli LA, Anderson JF, Barbour AG. The etiologic agent of Lyme disease in deer flies, horse flies, and mosquitoes. $J$ Infect Dis 1986;154:355-8.

6 Steere AC, Green J, Schoen RT, et al. Successful parenteral penicillin therapy of established Lyme arthritis. $N$ Engl J Med 1985;312:869-74.

Correspondence to Dr D Nadal, Department of Pediatrics, University of Zurich, Steinwiesstrasse $75, \mathrm{CH}-8032$ Zurich, Switzerland.

Received 15 June 1987

\title{
Blood counts in extremely low birthweight infants
}

\author{
N McINTOSH, C KEMPSON, AND R M TYLER
}

South West Thames Regional Neonatal Unit, St George's Hospital, London

SUMmary White blood, neutrophil, and platelet counts were higher in 101 infants with appropriate weight for gestational age than in 42 infants who were small for gestational age. The recognised postnatal rise in counts was seen in the infants of appropriate weight, but in the infants who were small for gestational age the counts fell for the first three days. 